\title{
Autoimmunpankreatitis oder Pankreaskarzinom?
}

\author{
Die Autoimmunpankreatitis ist \\ eine seltene Erkrankung, die häufig \\ primär als Pankreaskarzinom fehl- \\ interpretiert wird. Die Erhöhung des \\ Serum-IgG4-Spiegels und die Be- \\ teiligung anderer Organe sprechen \\ jedoch für eine Autoimmunpankre- \\ atitis.
}

— Dies ist das Ergebnis einer klinischen Studie, deren Ziel es war, eine diagnostische Strategie zur Unterscheidung dieser beiden Erkrankungen zu entwickeln. Eingeschlossen in die Studie wurden 48 Patienten mit einer Autoimmunpankreatitis und 100 Patienten mit einem Pankreaskarzinom.

Fand sich eine diffuse Pankreasvergrößerung ohne fokale Veränderung, so handelte es sich immer um eine Autoimmunpankreatitis, obwohl nur in
75\% ein erhöhter Serum-IgG4-Spiegel und/oder eine Beteiligung eines anderen Organs vorlag. Bei Patienten mit einer fokalen Pankreasvergrößerung bzw. einer karzinomverdächtigen Raumforderung, die jedoch letztendlich kein Karzinom hatten, fand sich immer ein zweifach oberhalb der Norm gelegener Serum-IgG4-Spiegel und/oder eine Beteiligung anderer Organe. Bei Patienten mit einer Autoimmunpankreatitis ohne serologischen Hinweis und/oder eine Beteiligung anderer Organe musste zur Sicherung der Diagnose eine Pankreasbiopsie, eine Steroidtherapie oder eine Resektion durchgeführt werden.

\section{Kommentar}

Wenn das Pankreas bei der sonografischen oder computertomografischen Dia- gnostik verändert ist und das Vorliegen eines Pankreaskarzinoms diskutiert wird, lässt sich mithilfe des Serum-IgG4-Spiegels und des Nachweises der Beteiligung anderer Organe eine zuverlässige Abgrenzung durchführen. Aber auch dann, wenn der Serum-IgG4-Spiegel im Normbereich liegt und keine Beteiligung anderer Organe vorliegt, ist eine Autoimmunpankreatitis nicht mit letzter Sicherheit ausgeschlossen. Bei ca. 30\% der betroffenen Patienten lässt sich die Diagnose nur mittels einer Pankreasbiopsie, eines Steroidtherapieversuchs oder eines chirurgischen Eingriffs definitiv klären.

P. Stiefelhagen =

- S.T. Chari et al.

A diagnostic strategy to distinguish autoimmune pancreatitis from pancreatic cancer. Clin. Gastroenterol.Hepatol.7 (2009) 1097-1103 